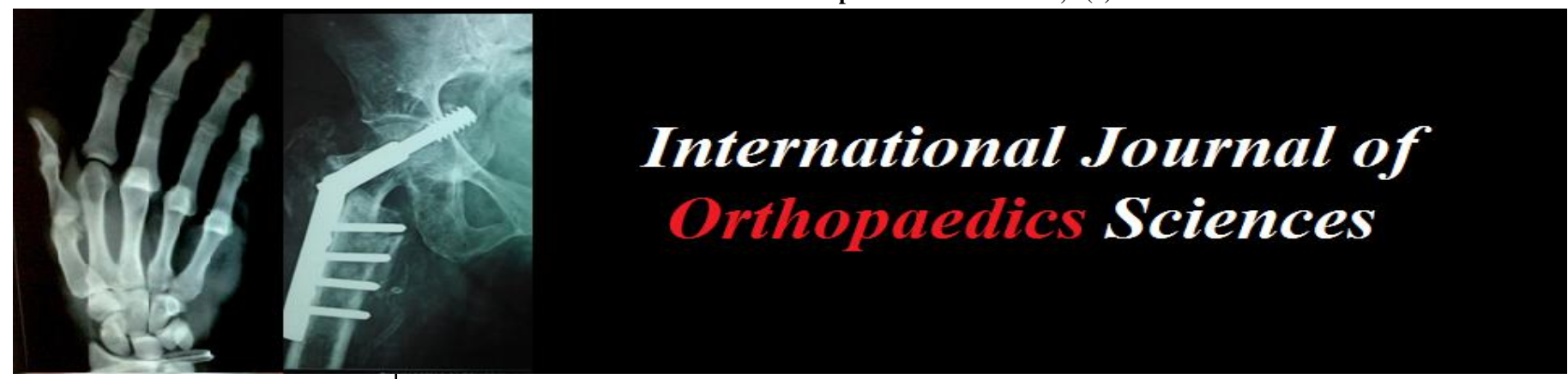

ISSN: $2395-1958$

IJOS 2019; 5(3): 345-350

(C) 2019 IJOS

www.orthopaper.com

Received: 21-05-2019

Accepted: 25-06-2019

Dr. Vrajesh R Shah

Consultant Orthopedic Surgeon, Viroc Hospital, Vadodara,

Gujarat, India

Dr. Rajiv C Paradkar

Consultant Orthopedic Surgeon,

Viroc Hospital, Vadodara,

Gujarat, India

Dr. Kishan K Zinzuwadia

Fellow in Arthroplasty, Viroc

Hospital, Vadodara, Gujarat,

India

Dr. Parita Jhaveri

Author and Physiotherapist

(Evaluator), Viroc hospital,

Vadodara, Gujarat, India
Correspondence

Dr. Vrajesh R Shah

Consultant Orthopedic Surgeon,

Viroc Hospital, Vadodara,

Gujarat, India

\section{A case report of peri prosthetic fracture after total knee arthroplasty in rheumatoid arthritis patient treated with revision hinge TKR}

\author{
Dr. Vrajesh R Shah, Dr. Rajiv C Paradkar, Dr. Kishan K Zinzuwadia and \\ Dr. Parita Jhaveri
}

DOI: https://doi.org/10.22271/ortho.2019.v5.i3f.1554

\begin{abstract}
We follow a new classification for periposthetic fractures which takes into account the status of the prosthesis, the quality of distal bone stock, and the reducibility of the fracture. We presented a case of 64 year old osteoporotic rheumatoid arthritic female with bilateral periprosthetic fracture treated with revision hinge TKR.
\end{abstract}

Keywords: Rheumatoid arthritis, periprosthetic fracture, revision TKR

\section{Introduction}

The management of periprosthetic fracture around the knee remains a challenging problem. The objective of this article was to review the general concepts, treatment algorithms, and the overall treatment outcomes of femoral and tibial periprosthetic fractures after total knee arthroplasty in rheumatoid arthritis patient. We follow a new classification for periposthetic fractures which takes into account the status of the prosthesis, the quality of distal bone stock, and the reducibility of the fracture ${ }^{[1]}$. Type I fractures are those occurring in patients with good bone stock with the prosthesis being fixed and well positioned. Type IA fractures are either nondisplaced or easily reducible and can be treated conservatively. Type IB fractures are irreducible and require reduction and internal fixation. Type II fractures are defined as those occurring also in patients with good bone stock and being reducible, but either the components are loose or malpositioned. These fractures are treated by revision arthroplasty. Type III fractures are reducible or irreducible fractures that occur in patients with poor bone stock and in the vicinity of loose or malpositioned components. These fractures are treated by revision surgery.

\section{Case report}

A 64 years old female with rheumatoid arthritis and bilateral total knee replacement operated 3 years back elsewhere presented to us in causalty with history of trivial_fall, following which she had difficulty in weight bearing. Patient had undergone routine examination and $\mathrm{X}$ rays. Patient's $\mathrm{x}$ ray showed left side distal femur periprosthetic medial condyle fracture which caused implant loosening and right side tibial implant loosening. Patient had type III periprosthetic fracture according to classification described above. Until this time she was completely asymptomatic and she was on anti-rheumatoid drugs since prolong time. Blood examination and other pre-operative reports showed all infective markers within normal limits and no any other signs of infection. After aneasthetic and physician fitness patient was planned for revision surgery first on left side followed by right side with the distance of 3 days.

\section{Surgical procedure}

Patient was placed in supine position on radiolucent table for both side revision TKR. On both sides standard median paraptellar approach taken. Previous TKR implants were removed and all scarred tissue removed. Medial and lateral collateral ligaments released and any remained 
Bone cement removed. Pulse lavage was used to remove any remaining debris. Revision hinge Knee system with distal femur and posterior femur augments were used with gentamycin cement.

Post operatively patient was kept on teriparatide injections for 6 months. Post-operative patient was kept in long knee brace for 3 weeks. Post-operative weight bearing with walker started immediately and bed side flexion up to 30 degree and quadriceps strengthening physiotherapy was included in protocol. Post-operative knee flexion was increased gradually and high sitting was allowed after 3 weeks. At 6 weeks follow up patient was able to walk freely without walker and knee flexion in both knees was up to around 120 degrees and no extensor lag on both sides.

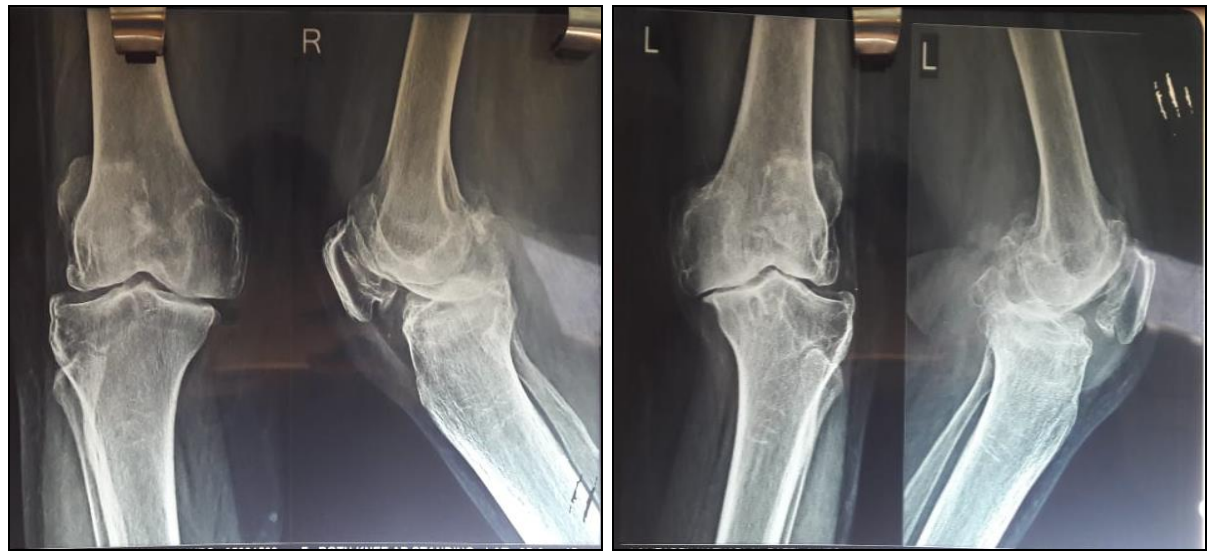

Fig 1: X ray shows bilateral knee showing severe osteoarthritic changes
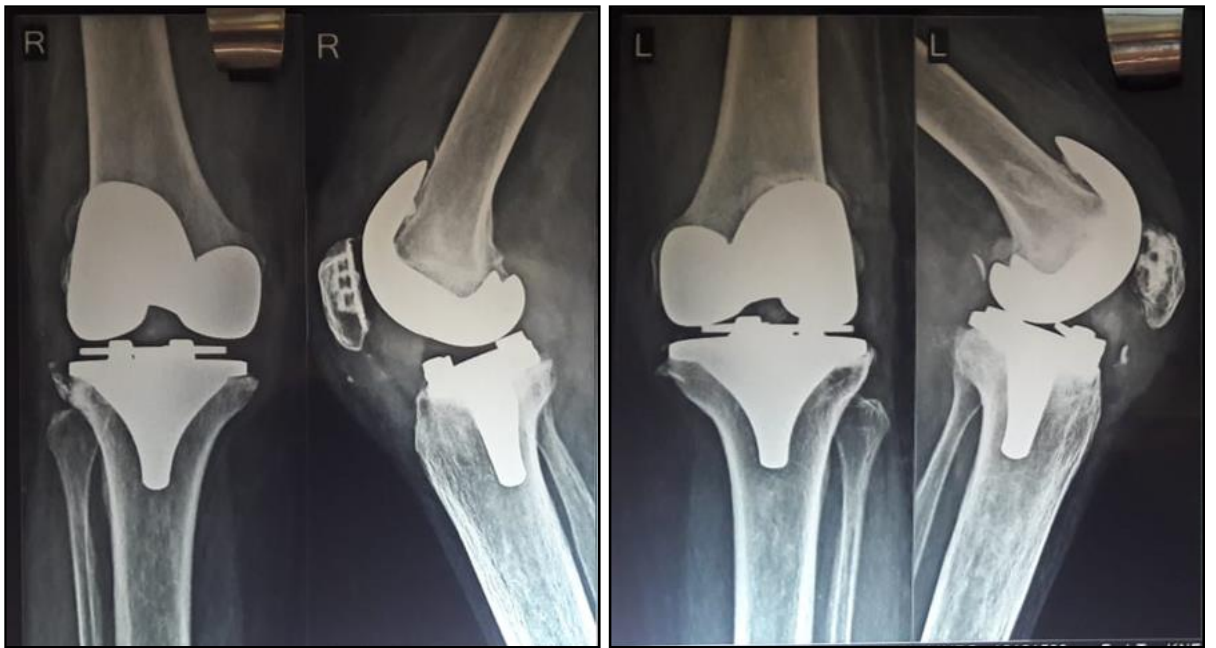

Fig 2: X ray bilateral knee-AP and Lateral showing $1^{\text {st }}$ post op status
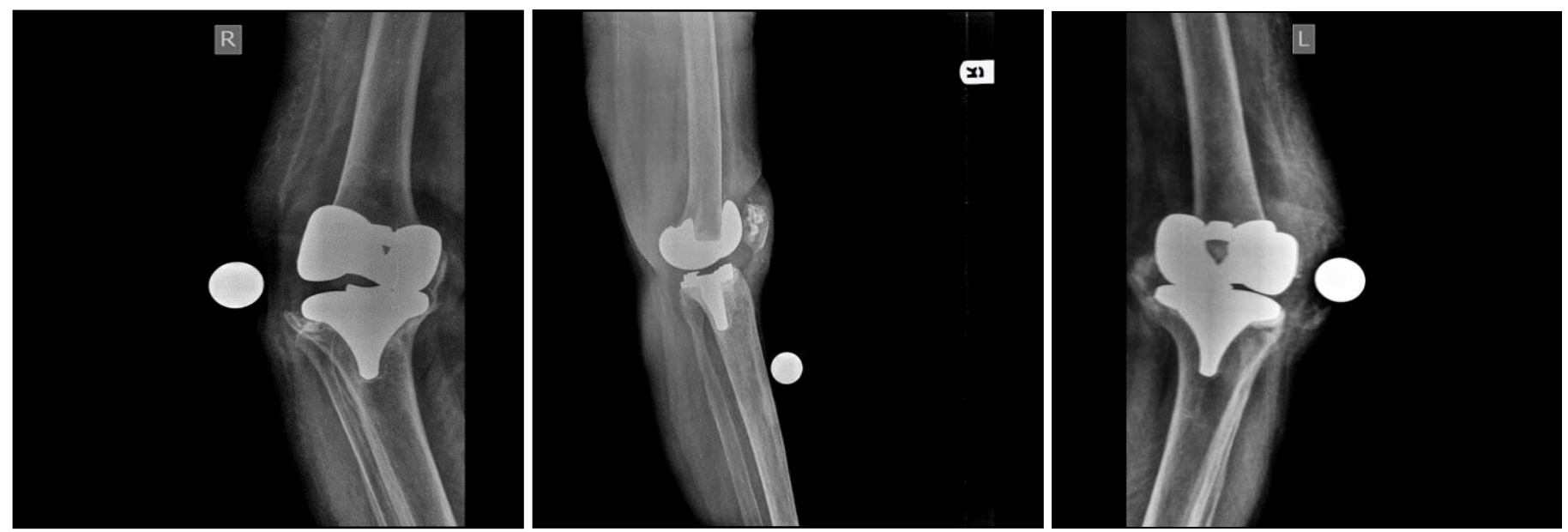


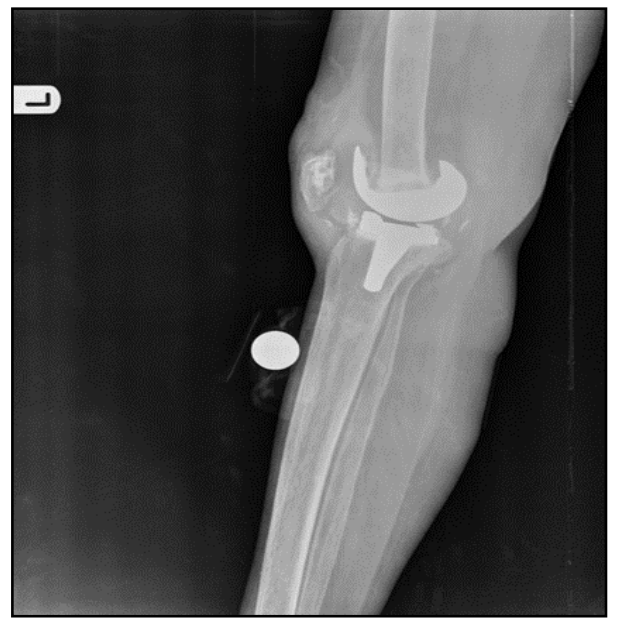

Fig 3: $\mathrm{X}$ ray both knee $-\mathrm{AP}$ and Lateral shows $2^{\text {nd }}$ pre op status
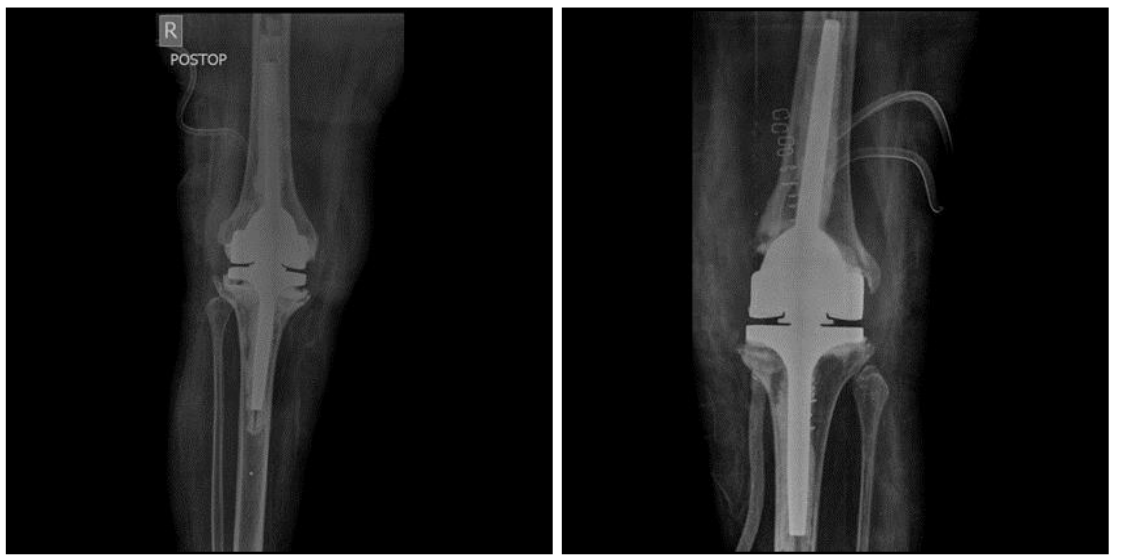

Fig 4: $\mathrm{X}$ ray shows 2 nd post op status of both knee
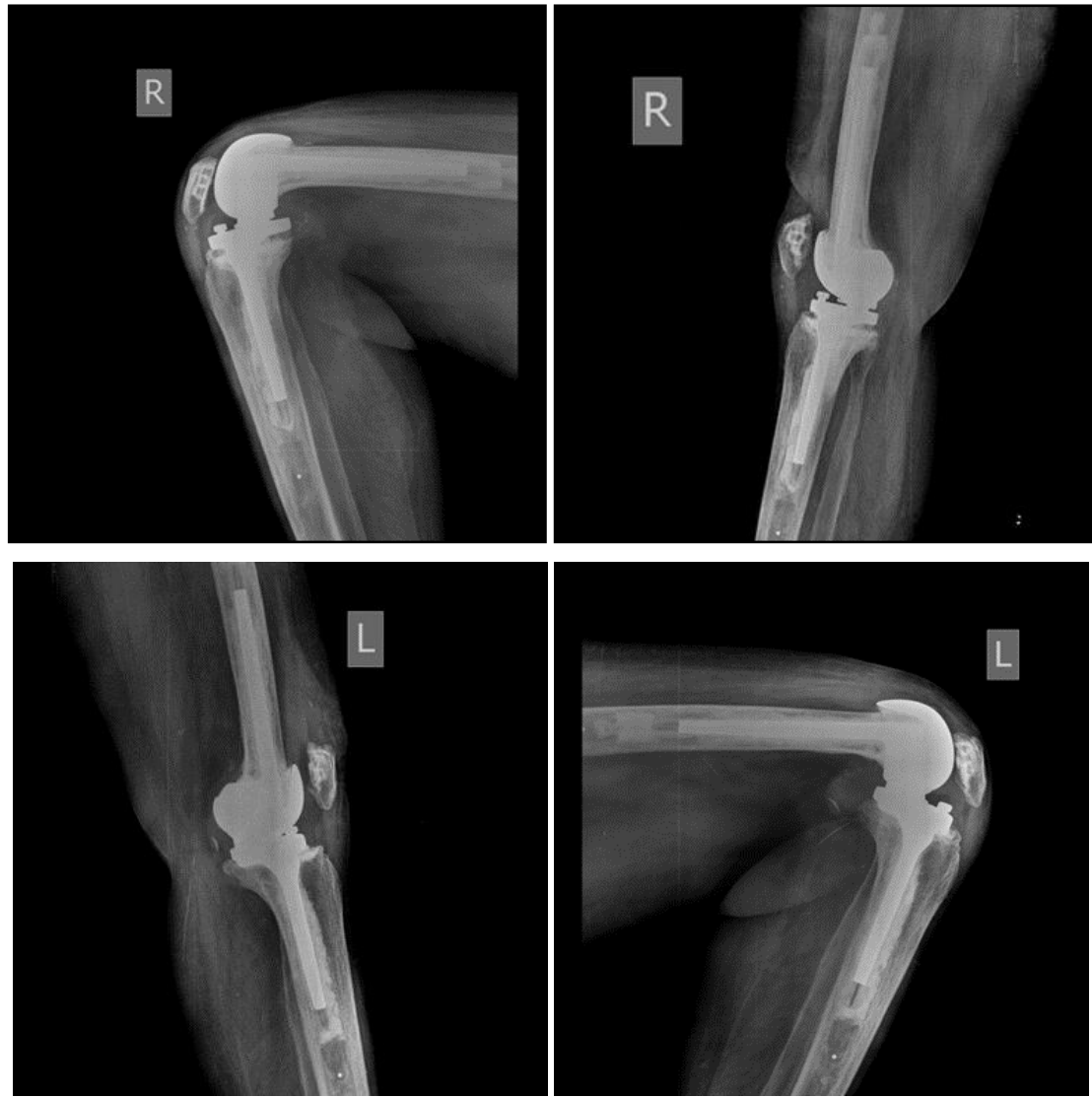

Fig 5: $\mathrm{X}$ ray both knee-AP and Lateral 6 months FU 

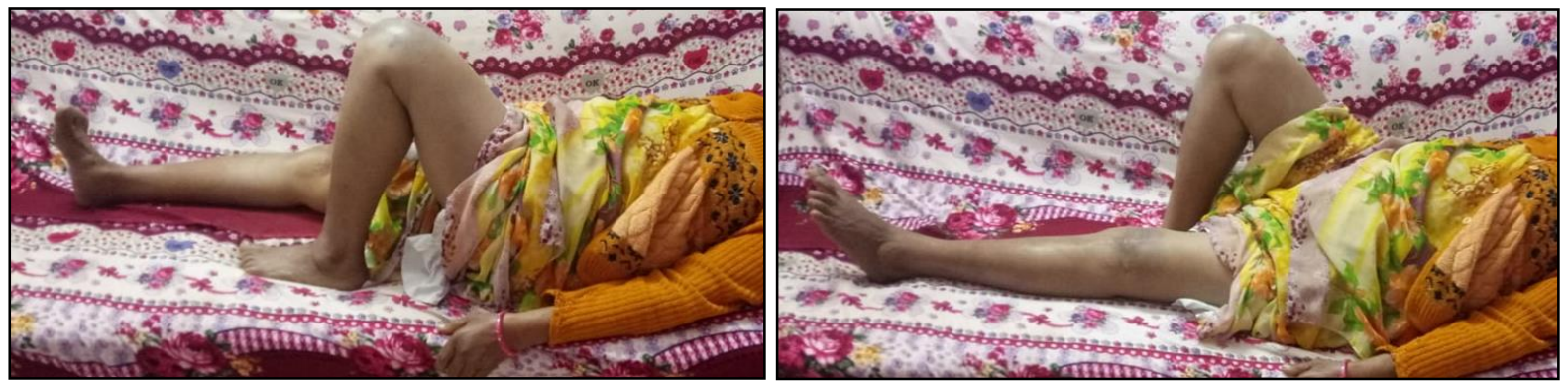

Fig 6: Post-operative knee flexion and extension after 6 months FU

\section{Discussion}

Periprosthetic fracture after TKA can occur in any patient. However, several predisposing factors have been identified, the most important of which relates to osteopenia. ${ }^{11,17} \mathrm{~A}$ number of conditions may lead to poor bone stock including old age, chronic use of corticosteroids, and rheumatoid arthritis (RA) $[3,6,8,11,16,17,27]$. Other conditions include the presence of stress risers such as screw holes around the knee, local osteolysis, stiff knee, and anterior femoral notching [2, 5, $8,11,17,22,27$. Patients with neurological abnormalities such as epilepsy, Parkinson's disease, cerebellar ataxia, myasthenia gravis, poliomyelitis, cerebral palsy, or undefined neuropathic joints are also at risk of periprosthetic fractures around the knee ${ }^{[8]}$. No clear relationship between postoperative component malalignment and subsequent periprosthetic femoral fracture has been identified ${ }^{[27]}$. However, marked varus malalignment of the tibia is thought to be a potential etiological factor in tibial periprosthetic fractures ${ }^{[24,30]}$. More tibial periprosthetic fractures than supracondylar femoral fractures are likely to occur in the presence of component loosening.

\section{Types of periprosthetic fractures}

Intraoperative femoral fracture can be divided into two groups: diaphyseal and metaphyseal fractures. Diaphyseal femoral fractures (Usually anterior or anterolateral cortical penetration) occur because of malpositioning of the intramedullary (IM) guide. The majority of these fractures may go undetected intraoperatively and are only noted during postoperative radiographic surveillance. [11, 23] The metaphyseal region of the femur may also experience fractures intraoperatively. These fractures are intercondylar splits or complete fracture of one or two condyles. These fractures can occur with some frequency in patients with osteopenia. Technical factors such as improper bone cuts, aggressive impaction of boxed posterior stabilized femoral component, and eccentric insertion of the trial component (particularly during revision surgery) are likely to contribute to this problem ${ }^{[23]}$. Because of the strong, dense nature of the proximal tibia, intraoperative periprosthetic tibial fracture is rare ${ }^{[12]}$. However, intraoperative tibial fractures do occur and are more common in revision surgery than in primary surgery [12]. Some factors resulting in tibial periprosthetic fracture include forceful retraction of well-fixed tibial component, eccentric cement removal, aggressive impaction of tibial component, and performing tibial tubercle osteotomy ${ }^{[12]}$. Theoretically, posterior stabilized knees are more vulnerable to intraoperative tibial fracture than cruciate retaining knee system. These fractures usually occur during impaction of posteriorly oriented tibial component with stem, are vertical in pattern, and are often undisplaced ${ }^{[11]}$. Cortical penetration around the tibia can also occur because of eccentric preparation of the canal ${ }^{[11]}$. The most common and challenging periprosthetic fracture after TKA is supracondylar femoral fracture, which usually occurs in the distal $1 / 3(15$ $\mathrm{cm}$ ) of the femur. These fractures are generally the result of low energy trauma ${ }^{[16]}$. The fracture may be more proximal in patients with a stemmed femoral component when the forces are transmitted to the tip of the stem or a region proximal ${ }^{[34]}$. Rorabeck and Taylor [34] proposed a classification for supracondylar femoral periprosthetic fracture that considered fracture displacement and fixation status of the femoral component. Type I fracture was undisplaced; Type II fracture had displacement of greater than $5 \mathrm{~mm}$ or greater than $5^{\circ}$ of angulation without component loosening; and Type III fracture was a supracondylar fracture with loosened component regardless of fracture displacement ${ }^{[34]}$. We followed a new classification system for femoral periprosthetic fractures. The most important factors include the amount of bone (volume and density) in the distal fracture fragment, the position and the fixation status of the component, and the fracture reducibility (Table 1). Based on this classification there are three types of fractures. Type I fractures occur in patients with good bone stock with the prosthesis being fixed and well positioned. Type IA fractures are either non-displaced or easily reducible and can be treated conservatively. Type IB fractures are irreducible and require reduction and internal fixation (Fig 1). Type II fractures are reducible fractures with adequate distal bone, but with a malpositioned or a loose component. These fractures are treated by revision of the component to a long stem component (Fig 2). Type III fractures are severely comminuted fractures with inadequate distal bone for fixation or support of a conventional component are best treated with prosthetic replacement (distal femoral replacement). Felix et al 12 reviewed 102 tibial periprosthetic fractures and classified them based on the anatomical location and component fixation. Four types of fractures were defined (Table 2) ${ }^{[12]}$. Type I fractures were most common and occurred at the tibial plateau ${ }^{[12]}$. They were thought to be stress fractures resulting from varus malalignment or loosening of the tibial component ${ }^{[12]}$. This type of fracture occurred more commonly with the early design of total knee systems without a tibial keel or stem ${ }^{[12]}$. Type II fractures occurred around the prosthetic stem as a result of trauma and were the second most common ${ }^{[12]}$. The presence of extensive osteolysis was thought to be critical to induce this type of fracture [12]. Type III fractures occurred distal to the component and did not result in component loosening ${ }^{[12]}$. Type IV fractures were defined as those involving the tibial tuberosity and were noted to be extremely rare ${ }^{[12]}$.

\section{Conclusion}

We followed a new classification system for femoral periprosthetic fractures. The most important factors include the amount of bone (Volume and density) in the distal fracture 
fragment, the position and the fixation status of the component, and the fracture reducibility ${ }^{[1]}$. Osteoporosis due to rheumatoid arthritis can cause periprosthetic fracture even with trivial trauma. Treatment of type III periprosthetic femur fracture and type II tibial component loosening can be very well treated by proper preoperative planning, revision TKR and proper post-operative physiotherapy and osteoporosis treatment protocol as we can see in our case report. So we can inferred from this study that treatment of ostroporosis is equally important as much as treatment of osteoarthritis to prevent revision surgery after TKR. A study with better design, large number of subjects and better level of evidence will further clarify the management of periprosthetic fracture in rheumatoid arthritis.

\section{Consent}

For this case to be published patient satisfactorily given informed consent for history, physical examination and publishing clinical photos and other relevant details.

\section{References}

1. Kang-1l Kim, Kenneth A. Egol, William J. Hozack, Javed parvizi. Periprosthetic fractures after total knee arthroplasties. Clinical Orthopedic and Related Research. 2006; 446:167-175.

2. Althausen PL, Lee MA, Finkemeier CG, Meehan JP, Rodrigo JJ. Operative stabilization of supracondylar femur fractures above total knee arthroplasty a comparison of four treatment methods. J Arthroplasty. 2003; 18:834-839.

3. Berry DJ. Periprosthetic fractures after major joint replacement. Epidemiology: hip and knee. Orthop Clin North Am. 1999; 30:183-190.

4. Bezwada HP, Neubauer P, Baker J, Israelite CL, Johanson NA. Periprosthetic supracondylar femur fractures following total knee arthroplasty. J Arthroplasty. 2004; 19:453-458.

5. Cain PR, Rubash HE, Wissinger HA, McClain EJ. Periprosthetic femoral fractures following total knee arthroplasty. Clin Orthop Relat Res. 1986; 208:205-214.

6. Chen F, Mont MA, Bachner RS. Management of ipsilateral supracondylar femur fractures following total knee arthroplasty. J Arthroplasty. 1994; 9:521-526.

7. Cordeiro EN, Costa RC, Carazzato JG, dos Santos Silva J. Periprosthetic fractures in patients with total knee arthroplasties. Clin Orthop Relat Res. 1990; 252:182-189.

8. Culp RW, Schmidt RG, Hanks G, Mak A, Esterhaj JL, Heppenstall RB et al Supracondylar fracture of the femur following prosthetic kneearthroplasty. Clin Orthop Relat Res. 1987; 222:212-222.

9. Dorr LD. Fractures following total knee arthroplasty. Orthopedics. 1997; 20:848-850.

10. Egol KA, Kubiak EN, Fulkerson E, Kummer FJ, Koval KJ. Biomechanics of locked plates and screws. J Orthop Trauma. 2004; 18:488-493.

11. Engh GA, Ammeen DJ. Periprosthetic fractures adjacent to total knee implants. Treatment and clinical results. Instr Course Lect. 1998; 47:437-438.

12. Felix NA, Stuart MJ, Hanssen AD. Periprosthetic fractures of the tibia associated total knee arthroplasty. Clin Orthop Relat Res. 1997; 345:113-124.

13. Figgie MP, Goldberg VM, Figgie HE III, Sobel M. The result of treatment of supracondylar fracture above total knee arthroplasty. J Arthroplasty. 1990; 5:267-270.

14. Ghazavi MT, Stockley I, Yee G, Davis A, Gross AE.
Reconstruction of massive bone defects with allograft in revision total knee arthroplasty. J Bone Joint Surg Am. 1997; 79:17-25.

15. Hayakawa K, Nakagawa K, Ando K, Ohashi H. Ender nailing for supracondylar fracture of the femur after total knee arthroplasty five case reports. J Arthroplasty. 2003; 18:946-952.

16. Healy WL, Siliski JM, Incavo SJ. Operative treatment of distal femoral fractures proximal to total knee replacements. J Bone Joint Surg Am. 1993; 75:27-34.

17. Inglis AE, Walker PS. Revision of failed knee replacements using fixed-axis hinges. J Bone Joint Surg Br. 1991; 73:757-761.

18. Keenan J, Chakrabarty G, Newman JH. Treatment of supracondylar femoral fracture above total knee replacement by custom made hinged prosthesis. Knee. 2000; 7:165-170.

19. Kraay MJ, Goldberg VM, Figgie MP, Figgie HE III. Distal femoral replacement with allograft/prosthetic reconstruction for treatment of supracondylar fractures in patients with total knee arthroplasty. J Arthroplasty. 1992; 7:7-16.

20. Kregor PJ, Hughes JL, Cole PA. Fixation of distal femoral fractures above total knee arthroplasty utilizing the Less Invasive Stabiliza-tion System (L.I.S.S.). Injury. 2001; 32(3):SC64-SC75.

21. Lesh ML, Schneider DJ, Deol G, Davis B, Jacobs CR, Pellegrini VD Jr. et al The consequences of anterior femoral notching in total knee arthroplasty. A biomechanical study. J Bone Joint Surg Am. 2000; 82:1096-1101.

22. Lombardi AV, Mallory TH, Waterman RA, Eberle RW. SIntercondylar distal femoral fracture. An unreported complication of posterior stabilized total knee arthroplasty. J Arthroplasty. 1995; 10:643-650.

23. Lotke PA, Ecker ML. Influence of positioning of prosthesis in total knee replacement. J Bone Joint Surg Am. 1977; 59:77-79.

24. Maniar RN, Umlas ME, Rodriguez JA, Ranawat CS. Supracondylar femoral fracture above a PFC posterior cruciate-substituting total knee arthroplasty treated with supracondylar nailing. A unique technical problem. J Arthroplasty. 1996; 11:637-639.

25. McLaren AC, Dupont JA, Schroeber DC. Open reduction internal fixation of supracondylar fractures above total knee arthroplasties using the intramedullary supracondylar rod. Clin Orthop Relat Res. 1994; 302:194-198.

26. KD, Johnson EW Jr. Supracondylar fracture of the femur after total knee arthroplasty. J Bone Joint Surg Am. 1986; 68:29-43.

27. Murrell GA, Nunley JA. Interlocked supracondylar intramedullary nails for supracondylar fractures after total knee arthroplasty. A new treatment method. J Arthroplasty. 1995; 10:37-42.

28. Pao JL, Jiang CC. Retrograde intramedullary nailing for nonunions of supracondylar femur fracture of osteoporotic bones. J Formos Med Assoc. 2005; 104:5459.

29. Rand JA, Coventry MB. Stress fractures after total knee arthroplasty. J Bone Joint Surg Am. 1980; 62:226-233.

30. Ritter MA, Faris PM, Keating EM. Anterior femoral notching and ipsilateral supracondylar femur fracture in total knee arthroplasty. J Arthroplasty. 1988; 3:185-187.

31. Ritter MA, Keating EM, Faris PM, Meding JB. Rush rod 
fixation of supracondylar fractures above total knee arthroplasties. J Arthro-plasty. 1995; 10:213-216.

32. Rolston LR, Christ DJ, Halpern A, O'Connor PL, Ryan TG, Uggen WM. Treatment of supracondylar fractures of the femur proximal to a total knee arthroplasty. A report of four cases. J Bone Joint Surg Am. 1995; 77:924-931.

33. Rorabeck CH, Taylor JW. Periprosthetic fractures of the femur complication total knee arthroplasty. Orthop Clin North Am. 1999; 30:265-277.

34. Schroder HM, Berthelsen A, Hassani G, Hansen EB, Solgaard S. Cementless porous coated total knee arthroplasty: 10-year results in a consecutive series. J Arthroplasty. 2001; 16:559-567.

35. Sekel R, Newman AS. Supracondylar fractures above a total knee arthroplasty. A novel use of Huckstepp nail. J Arthroplasty. 1994; 9:445-447.

36. Simon RG, Brinker MR. Use of Ilizarov external fixation for a periprosthetic supracondylar femur fracture. $\mathbf{J}$ Arthroplasty. 1999; 14:118-121.

37. Smith WJ, Martin SL, Mabrey JD. Use of a supracondylar nail for treatment of a supracondylar fracture of the femur following total knee arthroplasty. J Arthroplasty. 1996; 11:210-213.

38. Sochart DH, Hardinge K. Nonsurgical management of supracondy-lar fracture above total knee arthroplasty. Still the nineties option. J Arthroplasty. 1997; 12:830834.

39. Thompson NW, McAlinden MG, Breslin E, Crone MD, Kernohan WG, Beverland DE. Periprosthetic tibial fractures following ce-mentless low contact stress total knee arthroplasty. J Arthroplasty. 2001; 16:984-990.

40. Wong P, Gross AE. The use of structural allograft for treating periprosthetic fractures about the hip and knee. Ortho Clin North Am. 1999; 30:259-264.

41. Zehntner MK, Ganz R. Internal fixation of supracondylar fractures after condylar total knee arthroplasty. Clin Orthop Relat Res. 1993; 293:219-224. 